\title{
O trabalho com dado e banco de dados: considerações por meio de uma teoria enunciativa da linguagem
}

The work with datum and database: considerations through and enunciative theory of language

\author{
Paula Ávila Nunes \\ Universidade Tecnológica Federal do Paraná - Curitiba, PR, Brasil \\ Valdir do Nascimento Flores \\ Universidade Federal do Rio Grande do Sul/CNPq - Porto Alegre, RS, Brasil
}

\begin{abstract}
Resumo: Objetiva-se discutir as noções de dado e de análise quando a teoria mobilizada é de base enunciativa, tendo em vista duas questões centrais: se as diversas teorias enunciativas interrogam a língua do ponto de vista semântico, tendo por objetivo o estudo daquilo que é singular na fala de um determinado locutor, como pode um estudo enunciativo ter como base um corpus e, mais ainda, constituir um banco de dados? Não seria a Enunciação, de certa forma, refratária à própria noção de estudo linguístico com base em corpora? Em resposta a esses dois questionamentos, apresentamos o exemplo da construção de um banco de dados de distúrbio de linguagem - o ENUNSIL (Banco de Dados Enunciação e Sintoma na Linguagem), já que, se a noção de dado é problemática à Enunciação, tais dificuldades aumentam exponencialmente quando o que está em jogo é a fala sintomática.
\end{abstract}

Palavras-chave: Transcrição; Enunciação; Banco de dados; Corpus.

\begin{abstract}
The objective is to discuss the notions of datum and analysis when the theory in question is an enunciative one, bearing in mind two central questions: if the several enunciative theories question language through a semantic point of view, aiming at studying what is singular in the speech of each speaker, how can an enunciative study be based on a corpus and, even more, constitute a database? Are enunciative studies not refractory, in a certain way, to the notion of linguistic study based on corpora? In order to answer these two questions, we present the example of a database of language disorders, ENUNSIL (Banco de Dados Enunciação e SIntoma na Linguagem), considering that, if the notion of datum is problematic to enunciative studies, such difficulties augment exponentially when symptomatic speech is at stake.
\end{abstract}

Keywords: Transcription; Enunciative studies; Database; Corpus.

\section{Introdução}

Não há trabalho de natureza científica que escape à problemática do dado e, em Linguística, tal aspecto se torna ainda mais caro, uma vez que a ferramenta para descrição e análise do dado, a língua, é igualmente o próprio dado. Tal particularidade, discutida em trabalhos anteriores (FLORES, 2006, 2010 e 2012; NUNES, 2007 e 2012), convoca-nos a recolocá-la na ordem do dia por uma necessidade de dupla natureza: teórico-epistemológica e prática. A primeira deriva do fato de haver diferentes maneiras de se trabalhar com corpus em Linguística e, independentemente da teoria assumida, o lugar ocupado pelo dado deve ser presente ao teórico/pesquisador. Logo, impõe-se ao pesquisador em Enunciação explicitar a sua perspectiva de entendimento de trabalho com um corpus. Em última análise, é preciso entender - e isso também em Enunciação - qual a relação do dado com a teoria. A segunda decorre das dificuldades de operar com conceitos enunciativos por aqueles que buscam empreender um estudo dessa ordem. E uma das dificuldades mais evidentes se refere à constituição do corpus de pesquisa e ao tratamento e análise de dados.

É por essas razões que este escrito tem a pretensão de contribuir para o trabalho de pesquisadores no campo enunciativo. Há algo, porém, que deve ficar claro: o que ora se apresenta - mesmo que vise a suprir essa "lacuna" com que se deparam os pesquisadores do campo da Enunciação quando o assunto é dado, corpus e banco de dados - não tem o objetivo de se estabelecer como um 
guia ou de enumerar prescrições sobre como o dado deve ser encarado nesse campo de estudos. Antes, o objetivo é, tão-somente, pôr em relevo e discutir noções caras a qualquer teoria linguística, especialmente a enunciativa, por motivos que deverão ficar claros mais adiante.

Ainda que vinculadas estritamente ao sistema de pensamento Émile Benveniste, as considerações tecidas neste texto terão encontrado destino apropriado se infundirem naqueles que as leem, benvenistianos ou não, enunciativistas ou não, a vontade de discutir o lugar que dado, corpus e banco de dados ocupam na teoria com que trabalham. Lugar esse que nunca é trivial ou dado de antemão, pois, como já afirmava Benveniste, em seu texto-tributo a Saussure, "a linguagem é o que há de mais paradoxal no mundo, e infelizes daqueles que não o veem" (BENVENISTE, 1995, p. 45). Compete a este texto poder mostrar um pouco desses paradoxos. Assim, é na tentativa de viabilizar uma maneira de tratamento do dado, do ponto de vista enunciativo, que este trabalho procura seu espaço.

Em linhas gerais, este texto apresenta reflexão sobre aspectos importantes a serem considerados para a elaboração de Banco de Dados (BDs) com o viés enunciativo, ao mesmo tempo em que busca descrever a experiência de construção de um BD específico, qual seja, o Banco de Dados ENUNSIL ${ }^{1}$, cuja principal característica é ser um BD de distúrbios de linguagem.

Com essa orientação, o que aqui propomos se subdivide em três partes: na primeira, tentaremos traçar alguns dos principais empecilhos que a noção de dado e seu armazenamento impõem ao campo enunciativo; na segunda, propomos uma solução, de cunho prático, a fim de ilustrar uma das diversas formas pelas quais os dados podem ser abordados no domínio em questão. Por último, ainda que cientes de nossas limitações, procuramos delinear algumas contribuições que permitam repensar o dado dentro do escopo teórico adotado, partindo para um olhar epistemológico do quadro teórico enunciativo que abrigue o dado de forma congruente aos seus preceitos teóricos.

Isso enfatizado, partimos do pressuposto de que o campo da Linguística da Enunciação propõe um novo eixo de organização de BDs, em que a própria noção de dado precisa ser revista. Ao tratar do dado pelo aporte teórico de uma Linguística que comporta elementos relativos

\footnotetext{
O ENUNSIL foi elaborado para suprir as demandas do grupo de pesquisa Linguística e o sintoma na linguagem: a instância da falha na fala, desenvolvido na Universidade Federal do Rio Grande do Sul (UFRGS), sob coordenação do professor Valdir do Nascimento Flores. Tal projeto foi o primeiro a ser desenvolvido pelo grupo em questão, sendo sucedido por Enunciação e Distúrbios de Linguagem: sobre os níveis de análise da fala sintomática. Atualmente, o grupo se encontra engajado no projeto intitulado $O$ aspecto vocal/fônico da enunciação nos distúrbios de linguagem: um estudo enunciativo dos distúrbios articulatórios com etiologia orgânica definida.
}

à subjetividade na linguagem, aspectos como método, objeto, transcrição, além da própria consideração sobre o que é um banco de dados, são intimamente tocados. Isso se deve a um motivo específico: as teorias enunciativas valorizam sobremaneira a singularidade dos fenômenos de linguagem. Ora, singularidade evoca irrepetibilidade; logo, é uma palavra que parece estar na contramão do que subjaz a um $\mathrm{BD}$, uma vez que a palavra banco evoca, exatamente, a ideia de repetibilidade, noção esta que poderia nos levar a planificar algumas diferenças essenciais para a consideração do dado. Este texto é uma tentativa, também, de equacionar essa problemática.

\section{PARTE I}

\section{A problemática do dado em Enunciação}

Abordar a criação de BDs pela ótica de uma teoria da Enunciação implica muito mais que simplesmente transpor o aporte teórico evocado para o âmbito da informática, ou para o da catalogação. Como anunciáramos, é preciso voltar às origens do que é o dado e do que ele representa dentro de um banco de dados. Assim, reproduzimos abaixo a definição proposta por Dubois et al. (2006, p. 158) para o verbete corpus, em seu Dicionário de Linguística:

Estabelece-se a gramática descritiva de uma língua a partir de um conjunto de enunciados: este é submetido à análise e constitui o corpus da pesquisa. É útil distinguir o corpus dos termos vizinhos que designam conjuntos de enunciados: o "universo" $e ́$ o conjunto dos enunciados encerrados em uma dada circunstância, até que o pesquisador tenha decidido se esses enunciados entrarão na totalidade ou em parte na matéria de sua pesquisa. (...) A totalidade dos enunciados recolhidos é o universo. A partir do universo dos enunciados reunidos, por assim dizer, a granel, o lingüista seleciona aqueles que vai submeter à análise (...). Só esses segmentos de enunciados é que serão submetidos à análise e que constituirão o corpus [grifos nossos].

Uma leitura da definição proposta nessa obra lexicográfica permite traçar algumas considerações: (a) tal como é proposto, o objeto a servir como dado é o enunciado; (b) de acordo com o propósito teórico, o pesquisador pode selecionar os dados que julga relevantes para sua análise; (c) se a seleção por parte do pesquisador é realizada com vistas a encontrar dados que suportem uma hipótese prévia, há uma orientação teórica que regula os dados aprioristicamente, tornando-os válidos para a pesquisa ou não.

É a partir dessas postulações - pensadas no âmbito da linguística descritiva, é preciso que se ressalte -, que tecemos algumas observações sobre como a Linguística 
da Enunciação poderia se posicionar teoricamente em face dessas afirmações.

\section{Enunciado ou enunciação: o que constitui o dado, afinal?}

A primeira questão levantada no item anterior - (a) diz respeito ao enunciado como dado. Partamos disso para pensarmos o truísmo dessa asserção para uma teoria enunciativa.

Sabendo que a Lingüística da Enunciação pode atuar tanto no nível do enunciado quanto no nível da própria enunciação, encarar o dado como um enunciado de língua falada ou escrita parece interessar, no máximo, a uma teoria preocupada em observar as marcas enunciativas deixadas no sistema linguístico. Logo, encontraria abrigo nessa definição somente o que, genericamente, se denomina de enunciado, sem que, com isso, se contemple aspectos da enunciação. Acresce-se a isso o fato de que o que se entende pelos termos enunciado/enunciação não é unânime na literatura da área²

$\mathrm{Na}$ tentativa de clarear os limites dessa dicotomia, estabelecendo o que é relevante para o âmbito dos dados em Enunciação, recuperamos uma máxima, proveniente da leitura de Benveniste: só há enunciado quando houver enunciação, ou, nas palavras do próprio autor, "antes da enunciação, a língua não é senão possibilidade de língua" (BENVENISTE, 1989, p. 83). Dito de outra forma, é somente pela e na enunciação que o enunciado deixa de ser virtual e passa a existir, tornando-se único. E é precisamente a passagem, ou conversão, em termos benvenistianos, da língua em discurso, que o teórico visa a observar. Assim, não basta que um BD comporte apenas os enunciados: é preciso dar acesso à enunciação ${ }^{3}$, aqui entendida no sentido benvenistiano, ou seja, como "este colocar em funcionamento a língua por um ato individual de utilização" (BENVENISTE, 1989, p. 82).

Além disso, é o próprio Benveniste quem chama a atenção para o fato de que "[é] preciso ter cuidado com a condição específica da enunciação: é o ato mesmo de produzir um enunciado, e não o texto do enunciado, que é o nosso objeto", ao que acrescenta que, "na enunciação, consideraremos, sucessivamente, o próprio ato, as situações em que ele se realiza, os instrumentos de sua realização" (ibid., p. 83 - grifo nosso).

De forma análoga, é preciso ter cuidado também com o que se concebe por "tomar a enunciação como

\footnotetext{
2 Ver, por exemplo, as diversas definições para os dois termos no Dicionário de Linguística da Enunciação (cf. Bibliografia).

3 Reconhecemos que é quase paradoxal dar acesso a algo a efemeridade da enunciação, sendo que esta só existe uma única vez, em uma condição de tempo e espaço precisa. Mesmo assim, tentaremos demonstrar mais adiante como viabilizar esse processo, ao menos em parte, quando descrevermos o BD que produzimos.
}

objeto", o que é entendido Fiorin (2005), relembrando as palavras de Kerbrat-Orecchioni, como a operação com um deslizamento semântico. Assim,

o linguista não mais opõe "a enunciação ao enunciado como o ato a seu produto, um processo dinâmico a seu resultado estático", mas, impossibilitado de estudar diretamente o ato da enunciação, busca "identificar e descrever os traços do ato no produto". Tem razão Kerbrat-Orecchioni, quando mostra a impossibilidade de descrever o ato de enunciação em si mesmo. A descrição do ato em si violaria o princípio da imanência, base da constituição da Lingüística como ciência autônoma (p. 31 - grifos do autor).

Também nós consideramos, como fazem os autores acima citados, que analisar a enunciação é partir de seu produto, o enunciado, como fonte de pistas que levem a compreender o funcionamento e a organização singular da enunciação para um determinado sujeito. Nesses termos, um BD deveria comportar não só enunciados, mas deveria também engendrar meios de acesso à enunciação e aos três critérios para se considerá-la, propostos por Benveniste: "na enunciação, consideraremos o ato, as situações em que ele se realiza, os instrumentos de sua realização" (op. cit., p. 83).

\section{Que tipo de dado está em jogo?}

Mesmo condicionando a existência do dado à presença da enunciação, há ainda outra questão, referente ao item (b), que indaga à teoria o tipo de dado que lhe é relevante.

Numa divisão didática, Coudry (1996) evidencia três tipos de dados presentes no seu ramo de atuação (neurolinguística), quais sejam: (i) o dado-evidência, mais relacionado a uma quantificação que exemplifica uma teoria; (ii) o dado-exemplo, construído a partir de hipóteses prévias, a fim de corroborá-las; (iii) o dadoachado, não construído e com a finalidade de servir tanto para fins de exemplos, quanto para suscitar novas hipóteses e análises.

Desses três, apenas o dado-achado parece servir mais plenamente aos propósitos da Teoria da Enunciação. $\mathrm{O}$ primeiro deles é refutado pela própria autora quanto à relevância para sua área de pesquisa. Segundo ela, há um "falso pressuposto sobre o qual se baseia a construção do dado-evidência: supõe-se que a língua é um sistema homogêneo e que esse sistema já está descrito e, ainda, que o teste é o porta-voz dessa descrição" (p. 180). Tal noção de homogeneidade vai de encontro à perspectiva enunciativa, uma vez que, em Enunciação, cada enunciado (substantivo) adquire um novo sentido a cada vez que é enunciado (verbo), impossibilitando que o sistema seja totalmente descrito, como prevê o dado-evidência. 
Refutamos também o segundo tipo de dado formulado por Coudry, já que, nessa linha de trabalho, o dado precede a teoria. Ao contrário do que supõe o dado-exemplo, a Teoria da Enunciação, poder-se-ia dizer, tenta devolver ao dado seu estatuto epistemológico de antecessor à teoria, já que os dados sempre advêm de uma língua em atividade, semantizada na sua atualização, resultado de um processo de apropriação do aparelho formal da língua, tal como exposto por Benveniste.

Essa rejeição imposta ao dado-exemplo leva-nos de imediato ao terceiro tipo, o dado-achado. Numa análise enunciativa, é $d o$ dado que emanam os indicativos de análise, o que parece convir à idéia de dado-achado. Assim como o mesmo enunciado pode ser gerado por inúmeras enunciações, únicas e irrepetíveis, o mesmo dado pode gerar inúmeras análises, também singulares, uma vez que sempre passarão pelo filtro de um sujeito. Ou seja, em Enunciação, não só o dado é singular, já que comporta a enunciação, mas também a própria análise é única e dependente do sujeito que a realiza.

Dessa forma, qualquer que seja a análise feita, ela terá sempre que se render ao domínio da palavra para ser explicada. E entrar no domínio da palavra é pressupor um sujeito que enuncia; e o produto verbal desse sujeito é sempre uma nova enunciação, novamente única e irrepetível, plena de subjetividade.

À guisa de síntese, em Enunciação, o dado não é jamais "dado". Isso se dá porque, tal como postulado no item (c), acima, uma observação, uma análise, nunca é teoricamente neutra, por já ser o início de uma descrição.

$\mathrm{Se}$ pudéssemos apenas realizar um ajuste terminológico na proposta de Coudry, tendo em vista o escopo da Enunciação, talvez o melhor termo seja dadodeterminante. Isto é, um dado que determina o foco da análise e os rumos que ela tomará.

\section{PARTE II}

\section{O papel de um banco de dados de base enunciativa}

Dedicamos a primeira parte deste texto à revisão de alguns dos óbices que se impõem aos teóricos enunciativos no que tange ao tratamento dos dados. As questões revisitadas serão importantes para pensarmos a construção de um BD, conforme exibimos nesta parte, e de suma importância para pensarmos algumas conclusões a que é possível chegar por meio do que foi exposto.

Se os itens até agora abordados são evidências da dificuldade de se trabalhar com dados em Enunciação, a construção de um $\mathrm{BD}$ assume uma problemática ainda maior quando, na base teórica desse $\mathrm{BD}$, está uma teoria da Enunciação que não se restringe à análise dos enunciados, mas considera o colocar a linguagem em funcionamento. Partindo da tríade estabelecida por Benveniste (pessoa-tempo-espaço), um BD corre o risco de mascarar justamente os três elementos que são de interesse do analista, à medida que vão se perdendo no processo intermediário ou na própria forma utilizada para armazená-lo. Ora, se um BD apresentar somente o produto da enunciação, rompe-se com a possibilidade de observação dos outros elementos referentes à cena enunciativa e à produção em si, observada por BertandGastaldy (1989):

É o papel principal de uma interface efetuar as alterações de representação para passar da máquina ao homem e vice-versa. Contudo, essa conversão corre o risco de eliminar dos enunciados originais um bom número de marcas das operações e processos necessários para uma transferência adequada de informações (sem página - tradução nossa).

Ou seja, a criação de um BD de base enunciativa necessita ter uma configuração muito específica para que algum acesso ao processo (a enunciação) não se perca ao longo das inúmeras etapas de armazenamento. Se pensarmos, a título de ilustração, no modo comumente adotado para transformar os dados em produtos armazenáveis (a transcrição), veremos, de imediato, que ela é um estágio intermediário no trato com os dados: ao mesmo tempo em que não resguarda a enunciação, isto é, o verdadeiro objeto a ser observado, tampouco é a análise propriamente dita. Isso requer que dispensemos algumas palavras sobre o papel da transcrição e sobre sua (im) possibilidade de se figurar como única possibilidade no armazenamento de dados.

\section{Algumas palavras sobre a problemática da transcrição}

Antes de justificar as escolhas das formas de armazenamento dos dados para o BD que propomos como exemplo - o Banco de Dados ENUNSIL (Banco de Dados Enunciação e Sintoma na Linguagem) -, cabe considerar que, sob a ótica da Enunciação, a transcrição não é suficiente para servir como dado. A insuficiência não exclui a transcrição como possibilidade de dado, mas atesta um caráter de não-totalidade ${ }^{4}$. E, uma vez que há algo que escapa à transcrição, esse resto que fica impedido de ser transcrito, ela deixa de ser o meio principal de representação do ato enunciativo.

É essa incapacidade de escrever tudo que se estabelece como barreira para o lugar da transcrição dentro

\footnotetext{
4 Prova disso é que o BD aqui aludido comporta um "sub-banco", formado de transcrições e análises já feitas dos dados apresentados por um medium não-escrito.
} 
de um BD. Mas, se há sempre uma "perda" inerente ao processo de transformação do falado no escrito, dada a própria natureza dessa mudança de meio, há igualmente algo que remanesce, justamente o que repousa na transcrição e garante-lhe lugar como dado, por ter algo a dizer.

Assim, transcrever, na perspectiva enunciativa, é considerar a irrepetibilidade da Enunciação. Entendida como um ato de enunciação como qualquer outro (portanto, como algo também da ordem da singularidade), a transcrição precisa ser vinculada ao sujeito que a produz. Cabe dizer que a transcrição é, nesse caso, um ato de enunciação que carrega as marcas daquele que enuncia, que transcreve, sendo condição da análise empreendida, sempre parcial e não-generalizável.

E quais as implicações dessa concepção de transcrição para o eixo de organização de dados que propomos? A mais importante é, indubitavelmente, que um BD advindo de uma teoria preocupada em analisar a enunciação em si (e não seu produto), não satisfeita com as limitações impostas pela transcrição, deve forjar meios para acessar aquilo que se esconde por trás do escrito, meios para se acessar aquilo que só é mostrado ${ }^{5}$.

No nosso caso, mais especificamente, por tratar-se de um $\mathrm{BD}$ que serve a análises de fonoaudiólogos, a utilização da imagem (e não só da escrita) como fonte de dados é fundamental. Ou seja, o Banco de Dados ENUNSIL também preserva imagens em vídeo como fontes dos dados. E isso porque, se objetivamos construir uma hipótese sobre o funcionamento da linguagem ${ }^{6}$ de cada locutor produtor dos dados, tal procedimento não poderá se dar apenas por meio da escrita, já feita com uma interpretação e análise particular, cujo ponto de vista é refletido no texto.

Em suma, analisar uma hipótese sobre o funcionamento da linguagem é tratar do que é próprio do funcionamento da linguagem e inerente a ele. Se a hipótese sobre o funcionamento da linguagem revela

\footnotetext{
5 Para uma discussão específica sobre Enunciação e transcrição, Flores (2006), conforme bibliografia.

6 A noção de hipótese sobre o funcionamento da linguagem é central para os estudos do grupo mencionado na primeira nota. Para o leitor, no entanto, auxiliamos com a definição que a própria autora atribui ao termo: "falar sobre o funcionamento da linguagem para cada sujeito é lidar com possibilidades de organização desse funcionamento em um dado momento" (SURREAUX, 2006, p. 12-13). Em outras palavras, por mais que se rotule a fala de um paciente como desviante, há sempre uma lógica interna que a condiciona ou, nas palavras de Fiorin (op. cit.), há uma "infringência ordenada" das regras que regem o que chamaríamos de uma fala normal e que também é aplicável a uma fala dita desviante. Assim, toda e qualquer fala é observável, já que todas comportam um funcionamento singular e próprio de cada sujeito que enuncia, revelando seu modo único de estar na língua. Por último, é importante a lembrança de que o termo hipótese no sintagma aqui utilizado não é tributário de nenhuma vertente teórica específica. Seu uso, apesar de já ser um termo amplamente marcado no discurso científico, revela apenas a efemeridade da análise desse funcionamento: o clínico de linguagem deve estar sempre atento para que, à medida que é apresentado a novos enunciados, possa reformular essa hipótese.
}

justamente o mecanismo pelo qual o locutor se apropria da linguagem e, de certa forma, a própria lógica interna e específica de organização da língua deste, é justo que isso seja visto como intrínseco ao próprio funcionamento da linguagem e, portanto, indizível por meio de palavras, refutando a escrita como única possibilidade de dado.

\section{A utilização de imagem como dado}

Toda a discussão anterior é, na verdade, resultado do tipo de fazer científico em que se insere o saber enunciativo. Sobre isso, Benveniste (1989, p. 82-83) esclarece:

Na prática científica procura-se eliminar ou atenuar os traços individuais da enunciação fônica recorrendo a sujeitos diferentes e multiplicando os registros, de modo a obter uma imagem média de sons, distintos ou ligados. Mas cada um sabe que, para o mesmo sujeito, os mesmos sons não são jamais reproduzidos exatamente, e que a noção de identidade não é senão aproximativa mesmo quando a experiência é repetida em detalhe.

Como Benveniste explicita, o que buscamos não é uma média. Antes, nosso objeto é a singularidade do funcionamento da linguagem para cada um que a atualiza.

Estas diferenças dizem respeito à diversidade das situações nas quais a enunciação é produzida. (...) A enunciação supõe a conversão individual da língua em discurso (...) é ver como o "sentido" se forma em "palavras", em que medida se pode distinguir entre as duas noções e em que termos descrever sua interação (idem).

E, com tal objeto, é lícito afirmar que o que nos interessa observar é justamente o que antes descrevíamos como indizivel. Assim, na tentativa de estabelecer meios que suprissem aquilo que é eliminado da escrita, buscamos na imagem, no vídeo e no áudio, maneiras de mostrar o que não se pode dizer.

Dito de outra forma, não há enunciados que possam substituir o que a imagem veicula. Transcrevê-la, descrevê-la, ou simplesmente comentá-la envolve um posicionamento enunciativo por parte de quem o faz, tornando tudo o que pode potencialmente ser escrito sobre a imagem uma enunciação sobre a enunciação. Transcrever, descrever, comentar ou analisar é o ato mesmo de produzir uma enunciação acerca não somente de um dito, mas de um dizer.

\section{A estruturação singular de um banco de dados enunciativo - O ENUNSIL}

Ao buscar revisitar algumas noções-chave para a Lingüística da Enunciação no concernente ao tratamento do dado, seria possível apontar, num primeiro olhar, que 
a heterogeneidade, vista como essencial para um BD de cunho enunciativo, reside justamente na concepção teórica de dado. Enxergar um dado, sob o ponto de vista enunciativo, é atribuir-lhe o status de um prisma: o olhar do analista é a luz que incide sobre ele, e as luzes que dele se projetam são as diferentes análises possíveis, mas sempre dependentes e resultantes da configuração da incidência do olhar inicial. Observar o dado por um outro ângulo é alterar a forma dos espectros de luzes (conclusões da análise) que dele resultam. Se, como dissemos, essa é uma primeira aproximação, totalmente plausível em sua essência, tal interpretação exclui ainda uma série de potencialidades e instâncias de heterogeneidade que também compõem o BD e às quais dedicamos algumas das linhas que seguem.

Pensar a heterogeneidade presente em um BD como o ENUNSIL permite-nos traçar, numa tentativa didática de classificação, três eixos principais, responsáveis pelos traços de singularidade que emergem da ferramenta: a intersubjetividade com o usuário, a mobilização teórica, e a própria mudança na perspectiva de dado, antes referida. Vejamos cada um desses itens em mais detalhe.

\section{Da intersubjetividade com o usuário}

Como já observado por Bertrand-Gastaldy (1989), a comunicação nos meios de armazenamento de informação é, de início, diferente de uma realidade "cotidiana", por exemplo, já que os enunciadores dos enunciados primários não estão presentes quando o alocutário final entra em contato com a produção do primeiro, o que frequentemente ocorre com os textos escritos, mas não em situações de comunicação face a face. Sumariamente, uma configuração básica de um BD apresenta muito mais intermediários do que encontramos em meios naturais de enunciação, seja ela falada ou escrita, conforme é ilustrado abaixo.
Esse esquema, além de ilustrar os elementos intermediários presentes no processo de análise dos dados, mostra também como o próprio BD-ENUNSIL está de tal forma imerso na teoria que o conduz que reflete em si mesmo marcações enunciativas sutis, mas que merecem explicitação. A mais importante, eco dos pressupostos teóricos assumidos, é a própria subjetividade impressa no $\mathrm{BD}$, evidenciada nas escolhas lexicais e na arquitetura da ferramenta. Ou seja, ao criar um BD, é preciso ter em vista o público que irá utilizá-lo. Dessa forma, toda a construção é guiada pela imagem que se tem do outro e as tomadas de decisão, que se figuram como elementos marcadores de subjetividade de um BD, são, em última instância, fruto de uma intersubjetividade entre criador e utilizador ${ }^{7}$. Citamos, a título de exemplo, os mecanismos de busca, criados essencialmente com vistas a suprir as demandas dos consulentes ${ }^{8}$.

\section{Da mobilização teórica}

Nesse momento, cabe responder a uma pergunta que provavelmente está à deriva desde o início deste texto: o que este BD-ENUNSIL, voltado para a clínica dos distúrbios de linguagem, pode oferecer que outros ainda não tenham feito? A resposta para esse questionamento reside num pressuposto basilar para a confecção dessa ferramenta, notoriamente visível na forma em que a Lingüística da Enunciação concebe o sujeito.

Uma das grandes preocupações é que um BD enunciativo não tem seu propósito atendido ao ser um "banco de patologias". Explicamos: os dados não estão armazenados de acordo com uma classificação patológica geral, como pacientes com afasia, pacientes com gagueira etc. Antes, por tomar o sujeito que enuncia como base, o que temos é um BD de pacientes com uma fala particularmente organizada que se figura como uma fala desviante. Assim a definimos não apenas com
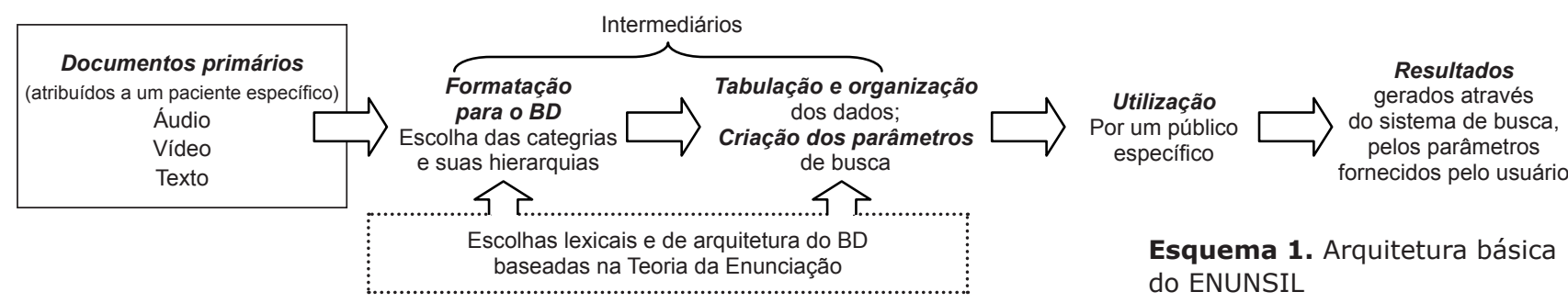

Esquema 1. Arquitetura básica do ENUNSIL

\footnotetext{
Lembremos aqui, novamente, Benveniste. A leitura de seu célebre texto "Da subjetividade na linguagem" (1958) permite interpretarmos a intersubjetividade como condição para a subjetividade. Ainda que a Lingüística da Enunciação se detenha sobre as marcas de subjetividade, esta parece só existir como resultado da intersubjetividade. Como nos afirma Benveniste, "é um homem falando que encontramos no mundo, um homem falando com outro homem" (p. 285 - grifos nossos) e, atribuindo à linguagem seu caráter dialógico ao propor "o discurso como linguagem posta em ação - e necessariamente entre parceiros - (...)", o autor entrega à intersubjetividade a condição de existência de subjetividade.
}

\footnotetext{
8 No BD em questão, temos a possibilidade de buscar informações através de vários filtros. É possível consultar pacientes por: clínica de origem, intervalo de idade, hipótese diagnóstica, sexo ou escolaridade; gravações em áudio e vídeo podem ser refinadas por paciente, por clínica, por sexo, por intervalo de idade, por hipótese diagnóstica e por escolaridade; textos podem ser filtrados por categorias (transcrição, artigo, análise etc.), por autor ou por palavrachave; por último, as produções de pacientes são organizadas por paciente, por clínica e por natureza da produção (foto, desenho, colagem etc.)
} 
vistas a emancipar o caráter patológico do dizer de cada sujeito, mas também ressaltar que o que se pretende é hierarquizar os dados de forma que esses estejam sempre ligados a um sujeito específico. Não se trata de um BD que abre possibilidades para a análise de uma ou outra patologia, mas um BD que observa como cada sujeito estrutura sua linguagem, ainda que essa seja desviante.

Ou seja, considerando-se que não há desvio, mas uma língua particularmente organizada por um paciente $\mathrm{X}$, então é necessário que todos os dados desse sujeito sejam a ele conectados, tornando necessária a inclusão dos sujeitos antes de qualquer outro dado. Dessa forma, temos a possibilidade de comparar casos apenas de um tipo de desvio, mas, para isso, partiremos não dá análise do desvio em si, mas da análise de diversos sujeitos com esse sintoma.

Advém dessa concepção de sujeito e de organização outra marca particular desse BD-ENUNSIL: as mudanças lexicais. Não mais podemos utilizar termos amplamente marcados no âmbito clínico, mas precisamos recorrer àqueles que transpareçam e corroborem um posicionamento teórico. É o caso, por exemplo, da substituição de diagnóstico por hipótese diagnóstica.

\section{Da mudança na perspectiva de dado}

Após traçar a conjuntura teórico-metodológica estruturante de um BD enunciativo, fica evidente a necessidade de se repensar um BD composto por transcrições, dada sua insuficiência. Ao propor um BD constituído também de imagens, não estamos delegando a solução para esse medium. Parece-nos mais coerente que a ferramenta possibilite acesso aos dois.

Mas por que pensar então, que um banco de imagens, por seu turno, também esbarra na insuficiência? Como já dito, e partindo do pressuposto de que a análise é uma leitura que se faz do funcionamento da linguagem de um sujeito, a mesma imagem pode gerar inúmeras análises, pois a leitura é sempre um movimento singular e pleno de subjetividade. Assim, nem somente a transcrição é suficiente, uma vez que já é leitura e, portanto, enunciação sobre outra enunciação, nem a imagem, uma vez que ainda não foi ouvida. A imagem não se sustenta por si mesma: é necessário que o analista a transcreva.

Assim, vimos, na articulação de imagem, som e transcrição, uma possibilidade de construção de análise. Enquanto a transcrição permite ao analista ler com o escrito, ainda que haja um resto que fica impossibilitado de ser nela apreendido, a imagem preserva esse resto, possibilitando recuperar o que invariavelmente impossível de ser transcrito. Transcrição e imagem, uma encontra na outra o alicerce para sua existência.

\section{Aspectos enunciativos preservados}

A configuração peculiar de um $\mathrm{BD}$, sob a ótica enunciativa, é de extrema relevância: o banco se instaura como possibilitador de recuperação do ato enunciativo. No entanto, sabendo da impossibilidade de atingir o ato enunciativo em si, o banco o transforma em fato $^{9}$, gerando implicação nas categorias de pessoa, tempo e espaço: não mais se está lidando com um eu-tu-aquiagora ou com um lá-alhures, mas com um aqui-agora "dilatado", marcando uma instância muito particular de organização da cena enunciativa. Especial porque, na abordagem do dado, há um desdobramento das categorias enunciativas: de certa forma, resguardamse o eu/tu/ele e o aqui/agora da enunciação original ${ }^{10}$, mas a análise da imagem permite que um novo eu/tu, aqui/agora tome lugar. O "novo" eu é constantemente atualizável a cada vez que um novo analista toma a cena como objeto de estudo, assim como um novo tu (leitor da transcrição) será condicionado pela presença do eu (transcritor). O mesmo acontece para o aqui/agora: ambos são re-atualizáveis.

Disso, podemos depreender uma mudança significativa: não mais é o eu que dá a possibilidade de enunciação aos sujeitos da cena clínica, tal como aconteceria em uma transcrição. Ao contrário, o eu toma a cena como objeto de análise, transformando-a, em última instância, em um ele, se lembrarmos a classificação de Benveniste ao apontar que ele é aquilo de que se fala.

Essa organização particular só é possibilitada pela mediação imagética. Ao utilizar a imagem, tornamola isenta da influência do analista no que tange à sua interpretação: se, na transcrição, o analista é obrigado a imprimir interpretações e significados ao que ouve, a imagem o permite observar, sem que para isso tenha, ele mesmo, que se enunciar.

\footnotetext{
9 Talvez seja necessária uma explicação acerca do termo fato enunciativo. Benveniste, em seus Problemas de Lingüística Geral I e II, diversas vezes faz uso do termo, sem que, no entanto, ofereça-nos uma definição clara. Propomos, assim, uma possível leitura: se, como afirma o autor, há que se considerar, em enunciação, o ato em si (cf. supra), (ainda que esse ato não seja apreensível, dada sua efemeridade) temos sua possibilidade de contemplação por meio do fato. $\mathrm{O}$ ato, único no espaço-tempo, tornase um fato. $\mathrm{O}$ que difere os dois parece estar justamente no seu nível de existência: o primeiro é a ação em si, o apropriar-se do aparelho formal da enunciação, acontecimento dinâmico e irrepetível; o segundo é a observação, o recorte feito de uma enunciação. E somente este último pode servir de objeto de análise.

10 Por exemplo, poderíamos considerar como o "eu" da enunciação original o terapeuta, e o "tu", o paciente, ambos intercambiáveis na relação subjetiva, e como "ele", a referência estabelecida em cada uma das cenas enunciativas da sessão de atendimento.
} 


\section{PARTE III}

\section{O papel de um BD enunciativo - conjunto de singularidades}

A assunção do dado, nos padrões em que antes nos referimos, não nos exime de desmembrar o sintagma banco de dados, interrogando-lhe que noção de banco subjaz ao termo. Como há mudança na perspectiva do que compõe essa ferramenta, espera-se também que algumas considerações sobre banco de dados sofram ressignificação quando inseridas no contexto teórico enunciativo.

Tratar de um banco, em Enunciação, não se iguala a elaborar um lugar onde os dados residam e formem um todo, através do qual se possa obter médias ou quantificações; tampouco é um conjunto de dados imersos numa homogeneidade. Antes, um banco comprometido com a teoria aqui mobilizada não é senão um conjunto de fatos, aptos a serem analisados. É nesse sentido que podemos dizer, retomando Dubois et al (2006), que o pesquisador "decide" que dados pertencerão a seu universo de análise, segundo suas intenções de estudo. Se a língua é virtualidade antes da enunciação, também o dado é virtual antes da análise: o fato enunciativo, verdadeiro constituinte do banco de dados, só emerge como dado uma vez que é tomado como objeto de observação.

$\mathrm{O}$ aporte teórico enunciativo propõe, então, que um banco, na impossibilidade de armazenar atos enunciativos, transforme-os em fatos. O fato seria equivalente, no caso de distúrbios de linguagem, às trocas linguageiras ocorridas em determinada sessão. É a partir da observação do fato que o analista faz seu recorte para análise. A esse recorte, daremos o nome de análise do fato enunciativo. Dessa forma, o BD permite-nos acompanhar todo o processo pelo qual o ato se transforma em fato e este, por sua vez, em análise, conforme o diagrama abaixo.

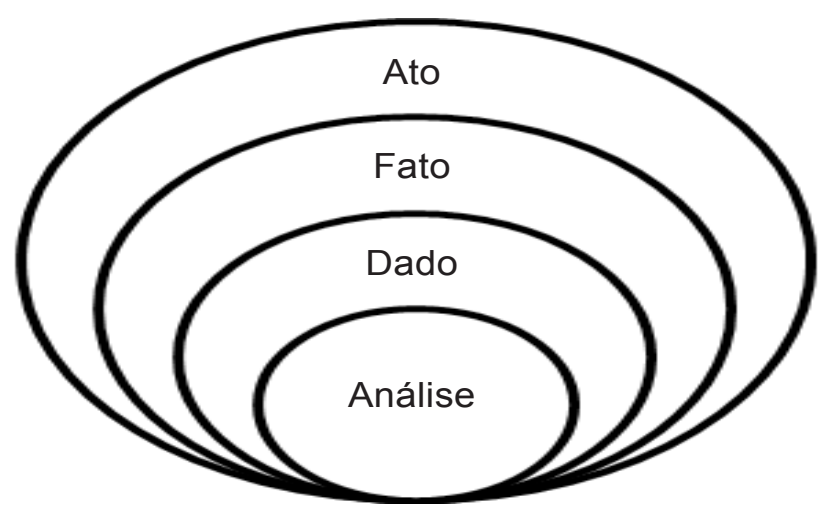

Fonte: NUNES, 2012.

Esquema 2. Do ato à análise em Enunciação
Banco, por seu turno, passa ser visto como uma forma de acesso às diferentes singularidades que o constituem, deixando de ser um fim, no qual todos os dados convergem, para ser um meio de viabilizar a conversão de fatos em dados. E a utilização de meio aqui não é fortuita. Se um BD se estabelece como intermediário do fato e da análise, ele é, então, protagonista de uma configuração enunciativa muito peculiar em que o observador não interage diretamente com o dado, mas chega a ele por outros meios, procedimento este que abala as categorias de pessoa, espaço e tempo, pois dá àquilo que é efêmero (a enunciação), condição de repetibilidade (cf. NUNES, 2012).

\section{À guisa de conclusão}

Dar fechamento a um texto em que tanto se abordou a impossibilidade de tudo dizer é lidar com esse constante incômodo de incompletude a que a língua nos sujeita. Ainda assim, há retomadas por fazer e considerações a serem explicitadas. Comecemos, pois, pela lingüística que norteou este estudo.

À medida que aumentam as interfaces da Lingüística da Enunciação com outras áreas do saber, torna-se necessário também refletir epistemologicamente acerca do lugar que certas noções ocupam no escopo teórico mobilizado. A apreciação do dado, até então pouco estudado, permitiu-nos tecer comentários e (re)construir sentidos. Tentou-se problematizar a própria noção de dado e suas implicações para a construção de um BD, mas buscou-se também ir além. Conceitos foram revisitados, re-semantizados para a área estudada e, esperamos, mais bem delineados para pesquisadores e teóricos.

Ao abordar a transcrição e toda sua problemática, além de elaborar hipóteses que dessem conta dos desdobramentos das categorias enunciativas, buscamos, na articulação da imagem com a própria transcrição, um meio de construção de análise. Sabendo que apagar a voz, apagar os traços enunciativos de quem analisa é apenas uma "ficção de apagamento", utilizando os termos de Authier-Revuz (1998), tentou-se forjar meios para que essa incapacidade de tudo dizer (ou de tudo transcrever) seja um pouco mais suportável, do nosso ponto de vista, do ponto de vista de lingüistas e sujeitos desejantes.

Para a clínica de linguagem, mesmo que nossas incursões no terreno sejam sempre reguladas por um olhar estranho, de um outro campo do conhecimento, procurou-se obviar algumas potencialidades da interface entre esses dois campos, na tentativa de evidenciar o que uma Lingüística voltada para o sujeito que enuncia, e não mais para a patologia que se observa, pode contribuir para o estudo de casos clínicos. Como antecipado já na introdução, não propomos soluções, mas apontamos 
caminhos que possibilitaram que essa articulação entre clínica e lingüística pudesse ser o mais relevante possível e que permitisse, dentro de seus limites, que a clínica de linguagem pudesse se deixar levar pelo sujeito que enuncia e sua singularidade. Uma clínica regulada pelo escrito, pelo dito e pelo dizer, estabelecendo uma tricotomia sobre a qual ambas as áreas ainda têm muito a dizer.

\section{Referências}

AUTHIER-REVUZ, Jacqueline. Palavras incertas: as nãocoincidências do dizer. Campinas: Editora da UNICAMP, 1998.

BENVENISTE, Émile. Problemas de Lingüística Geral I. $4^{\mathrm{a}}$ ed. Campinas: Pontes, 1995.

BENVENISTE, Émile. Problemas de Lingüistica Geral II. Campinas: Pontes, 1989.

BERTRAND-GASTALDY, Susanne. 1989. La problématique de l'énonciation dans les systèmes documentaires entièrement ou partiellement automatisés. Disponível em: <http:/www. ling.uqam.ca/sato/publications/bibliographie/Tatravmo.htm>. Acesso em 13 de fevereiro de 2016.

COUDRY, Maria Irma Hadler O que é o dado em neurolingüística? In: CASTRO, Maria Fausta Pereira (Org.). $O$ método e o dado no estudo da linguagem. Campinas: Unicamp, 1996. p. 179-194.

DUBOIS, Jean et al. Dicionário de Linguística. São Paulo: Cultrix, 2006

FIORIN, José Luiz As astúcias da enunciação: as categorias de pessoa, espaço e tempo. 2. ed. São Paulo: Ática, 2005.

FLORES, Valdir do Nascimento. Fato, nível da análise lingüística e transcrição: três operadores da análise enunciativa.
In: LEFFA, Vilson; ERNST, Aracy. (Org.). Linguagens. Metodologias de ensino e pesquisa. Pelotas: EDUCAT, 2012. p. $150-164$.

FLORES, Valdir do Nascimento. O lugar metodológico da análise da enunciação em relação aos níveis da análise lingüística. In: BATTISTI, Elisa; COLLISCHONN, Gisela. (Org.). Lingua e linguagem: perspectivas de investigação. Porto Alegre: Palotti, 2010. Vol. 1. p. 45-57.

FLORES, Valdir do Nascimento. Entre o Dizer e o Mostrar: a transcrição como modalidade de enunciação. Organon, UFRGS, Porto Alegre, v. 40-41, p. 61-75, 2006.

FLORES, Valdir do Nascimento et al. Dicionário de Linguística da Enunciação. São Paulo: Contexto, 2009.

NUNES, Paula Ávila. A prática tradutória em contexto de ensino (re)vista pela ótica enunciativa. 2012. $239 \mathrm{f}$. Tese (Doutorado) - Programa de Pós-Graduação em Letras, Instituto de Letras, Universidade Federal do Rio Grande do Sul, Porto Alegre, 2012.

NUNES, Paula Ávila. Aspectos enunciativos da construção de um banco de dados de distúrbios de linguagem. Apresentação no XIX Salão de Iniciação Científica da Universidade Federal do Rio Grande do Sul. Porto Alegre: UFRGS, 2007.

SURREAUX, Luiza Milano. Linguagem, sintoma e clínica em clínica de linguagem. 2006. 202 f. Tese (Doutorado) - Programa de Pós-Graduação em Letras, Instituto de Letras, Universidade Federal do Rio Grande do Sul, Porto Alegre, 2006.

Recebido: 28 de fevereiro de 2017

Aprovado: 21 de abril de 2017

Contato:

Paula Ávila Nunes<paulanunes@ufpr.edu.br> 